\title{
Micropropagação do maracujazeiro-do-sono
}

\author{
Flávia Carvalho Santos ${ }^{1}$, José Darlan Ramos², Moacir Pasqual ${ }^{3}$, Juliana Costa de Rezende \\ Fabíola Carvalho Santos ${ }^{4}$ Fabíola Villa
}

\section{RESUMO}

Em função da dificuldade de propagação de Passiflora setacea DC., técnicas de cultura de tecidos tornam-se alternativas viáveis. Objetivou-se estudar a germinação in vitro e determinar o melhor meio de cultivo na sua micropropagação. O presente trabalho constou de duas etapas, na primeira as sementes (sem escarificação, escarificadas na extremidade ou na parte mediana) na foram colocadas em $1 / 2 \mathrm{MS}$ e $30 \mathrm{~g} \mathrm{~L}^{-1}$ de sacarose, distribuído em tubos de ensaio e suplementado com zero, $20 \mathrm{ou} 40 \mathrm{mg} \mathrm{L}^{-1}$ de GA . $\mathrm{O}$ pH do meio foi ajustado para 5,8 antes da adição de 6,0 mg L $\mathrm{L}^{-1}$ de ágar. Após a inoculação das sementes nos meios de cultura, elas foram mantidas em sala de crescimento com luminosidade de $35 \mu \mathrm{mol} . \mathrm{m}^{-2} . \mathrm{s}^{-1}$, temperatura de $26 \pm 1^{\circ} \mathrm{C}$ e fotoperíodo de 16 horas. Assim que germinaram, as plântulas foram transferidas para tubos contendo meio MS, onde constituíram um segundo experimento, a fim de se testarem meios combinados com concentrações de sacarose. O delineamento experimental utilizado foi inteiramente casualizado, em esquema fatorial 3 x 3, quatro repetições e 15 sementes por parcela no primeiro experimento e 4 x 4, com quatro repetições e 3 plantas por parcela no segundo experimento. Melhores resultados na micropropagação foram obtidos em meio de cultivo MSM, associado a 28,51 e 28,74 $\mathrm{g} \mathrm{L}^{-1}$ de sacarose. Maior índice de velocidade de germinação foi verificado com uso de $20 \mathrm{mg} \mathrm{L}^{-1}$ de $\mathrm{GA}_{3}$, associado à escarificação na ponta da semente.

Palavras-chave: Passiflora setacea DC., maracujá, cultura de tecidos, in vitro.

\begin{abstract}
\section{Micropropagation of Passiflora setacea DC.}

Propagation of Passiflora setacea DC. is extremely difficult, therefore tissue culture techniques become a viable alternative. The objective of this study was to evaluate the in vitro germination and determine the best culture medium for micropropagation. This work was carried out in two stages; in the first, seeds were placed in $1 / 2$ MS culture medium and $30 \mathrm{~g} \mathrm{~L}^{-1}$ of sucrose, distributed in tubes and supplemented with different $\mathrm{AG}_{3}$ concentrations. The $\mathrm{pH}$ of culture medium was adjusted for 5.8 before adding $6.0 \mathrm{mg} \mathrm{L}^{-1}$ of agar. After seed inoculation, the cultures were kept in a growth room under $35 \mu \mathrm{mol} . \mathrm{m}^{-2} . \mathrm{s}^{-1}, 26 \pm 1^{\circ} \mathrm{C}$ and photoperiod of 16 hours. Just after germination, the seedlings were transferred to tubes containing $1 / 2 \mathrm{MS}$, constituting a second experiment, in order to test culture media with different sucrose concentrations. The experiments were arranged in a complete randomized design, in a 3x3 factorial, with four repetitions and 15 seeds/plot (first experiment) and a $4 x 4$ factorial, with four repetitions and 3 plants/plot (second experiment). The best results for micropropagation were obtanied in MSM medium with 28.51 and $28.74 \mathrm{~g} \mathrm{~L}^{-1}$ of sucrose. The highest germination speed index was obtained with $20 \mathrm{mg} \mathrm{L}^{-1}$ of $\mathrm{AG}_{3}$ combined with seed tip scarification.
\end{abstract}

Key words: Passiflora setacea DC., passion fruit, tissue culture.

Recebido para publicação em abril de 2008 e aprovado em setembro de 2009

${ }^{1}$ Engenheira-Agrônoma, Doutoranda em Fitotecnia/UFLA, Caixa Postal 3037, 37200-000, Lavras, Minas Gerais (MG), Brasil. flavinha3010@yahoo.com.br

${ }^{2}$ Professor adjunto do Departamento de Agricultura da Universidade Federal de Lavras/UFLA, Cx. P. 3037, 37200-000, Lavras, MG, mpasqual@ufla.br, darlan@ufla.br

${ }^{3}$ Engenheiros-Agrônomos, EPAMIG, UFLA, Cx. P. 3037, 37200-000 Lavras, MG. juliana_ufla@yahoo.com.br

${ }^{4}$ Graduação em Agronomia, Universidade Federal de Lavras/UFLA, Cx. P. 3037, 37200-000, Lavras, MG. fabiolacs@yahoo.com.br

5Pós-doutoranda em Fitotecnia, EPAMIG/FAPEMIG, Bairro Vargedo, Maria da Fé, MG. fvilla2003@libero.it 


\section{INTRODUÇÃO}

O cultivo do maracujazeiro ocupa, no Brasil, 34.000 hectares. Embora presente em todas as regiões, assume papel de destaque no Nordeste (43,3\% da produção brasileira) e Sudeste (41\%), sendo a Bahia, o Espírito Santo e São Paulo os principais produtores (IBGE, 2005). Além disso, o Brasil é o maior produtor mundial de frutos com aproximadamente 33 mil hectares plantados e produtividade média de $9.035 \mathrm{~kg} \mathrm{ha}^{-1}$ (Ruggiero, 2000). As espécies cultivadas comercialmente são a Passiflora edulis Sims (maracujazeiro-azedo e maracujazeiro-roxo) e a P. alata Curtis (maracujazeiro-doce) (Bernacci et al., 2005). Independentemente da espécie, existem problemas fitossanitários e de propagação que compromentem o seu cultivo comercial. As doenças provocadas por patógenos do solo constituem-se nas mais importantes, em termos de expressão econômica. Com o objetivo de aproveitar espécies resistentes nos programas de melhoramento ou utilizá-las como porta-enxertos em áreas afetadas, a variabilidade entre e dentro de espécies do gênero Passiflora para resistência a doenças e pragas tem sido estudada e caracterizada (Ruggiero, 2000).

O maracujazeiro-sururuca ou maracujazeiro-do-sono (P. setacea DC.), é uma espécie silvestre e pouco estudada com relação à propagação por via sexuada e às condições de armazenamento das sementes (Meletti et al., 2002). Vários autores (Junqueira et al., 2005; Braga et al., 2006) citam que essa espécie silvestre possui tolerância a algumas doenças e pragas, como resistência à morte precoce e fusariose, constituindo uma alternativa em potencial para uso como porta-enxertos. Porém, características como dormência das sementes e dificuldades no enraizamento das estacas são limitações que podem comprometer seu uso em plantios comerciais (Sousa \& Meletti, 1997; Manica et al., 2005).

De acordo com Passos \& Bernacci (2005), o estabelecimento in vitro de plantas de diversas espécies de maracujazeiro é essencial quando se deseja fazer a manutenção de germoplasma de Passiflora usando procedimentos biotecnológicos. Para tanto, devem estar disponíveis, na literatura, protocolos de assepsia para explantes obtidos de sementes, folhas, gemas e segmentos nodais, bem como protocolos para germinação de sementes. Em razão da desuniformidade e dificuldade de germinação de $P$. setacea DC., as técnicas de cultura de tecidos são alternativas para a sua propagação.

Os meios de cultura, por consistirem parte essencial desta técnica, necessitam de constante aprimoramento, buscando-se sempre o que proporcione maior germinação e propagação in vitro, gerando maior número de mudas frutíferas de qualidade e com menor custo (Pasqual, 2001). Podem-se encontrar vários meios para tal finalida- de, como MS (Murashige \& Skoog, 1962), WPM [(Wood Plant Medium) Lloyd \& McCown (1980)], MSM (meio MS modificado por Monteiro-Hara, 2000), BDS(Dunstan \& Short, 1977) e o meio DSD1 (Silva \& Doazan, 1995).

Objetivou-se estudar a superação de dormência na germinação in vitro e determinar o meio de cultivo que proporcione melhor micropropagação do maracujazeirodo-sono (Passiflora setacea DC.).

\section{MATERIAL E MÉTODOS}

\section{$1^{a}$ Etapa}

O experimento foi conduzido no Laboratório de Cultura de Tecidos Vegetais da Universidade Federal de Lavras (UFLA). Foram usadas sementes de maracujá-do-sono (Passiflora setacea, código CPAC MJ-12-01), provenientes de frutos do banco de germoplasma de Passiflora spp., da EMBRAPA Cerrados.

As sementes foram colocadas em béquer contendo 50 $\mathrm{mL}$ de água com duas gotas de detergente para a primeira lavagem. A seguir, elas foram enxaguadas em água corrente, utilizando-se peneira plástica, sendo posteriormente mergulhadas em álcool 70\% por 40 segundos. Para a retirada do arilo remanescente, utilizou-se o tecido Perfex ${ }^{\circledR}$. As sementes foram imersas em solução de hipoclorito de sódio (2\%) durante 20 minutos e submetidas a três lavagens em água destilada autoclavada.

O meio de cultura utilizado foi $1 \frac{1}{2} \mathrm{MS}$, acrescido de 30 $\mathrm{g} \mathrm{L}^{-1}$ de sacarose, $100 \mathrm{mg} \mathrm{L}^{-1}$ ) de mioinositol e concentrações de ácido giberélico $\left(\mathrm{GA}_{3}\right)$. O pH do meio foi ajustado para 5,8 antes da colocação de 6,0 $\mathrm{mg} \mathrm{L}^{-1}$ de ágar $\left(\mathrm{Merck}^{\circledR}\right)$. Os meios foram distribuídos em tubos de ensaio $(15 \mathrm{~mL} /$ tubo), sendo esses vedados com tampas plásticas e levados para autoclavagem à temperatura de $121^{\circ} \mathrm{C}$, por 20 minutos.

Os tratamentos constituíram-se de quatro concentrações de $\mathrm{GA}_{3}\left(0,20,30\right.$ e $40 \mathrm{mg} \mathrm{L}^{-1}$ no meio de cultura adicionadas ao meio de cultivo $1 / 2 \mathrm{MS}$, combinadas com ausência de escarificação, escarificação na ponta da semente (próxima do embrião) e escarificação no meio da semente. A escarificação foi realizada fazendo-se cortes com bisturi.

O ensaio foi instalado, em condições assépticas, em câmara de fluxo laminar horizontal desinfestadas com álcool 70\%. Os instrumentos (pinças, bisturis e placas de Petri ${ }^{\circledR}$ ) foram autoclavados e flambados. Após a introdução das sementes, o material foi colocado em sala de crescimento com luminosidade em torno de $35 \mu \mathrm{mol} \cdot \mathrm{m}^{-2} \cdot \mathrm{s}^{-1}$, temperatura de $26 \pm 1^{\circ} \mathrm{C}$ e fotoperíodo de 16 horas. Assim que germinaram, as plântulas foram transferidas para tubos de ensaio contendo meio de cultura MS (completo).

O delineamento experimental utilizado foi inteiramente casualizado, em esquema fatorial $3 \times 4$ (três tipos de 
escarificação x quatro concentrações de $\mathrm{GA}_{3}$ ), quatro repetições e 15 sementes por parcela na primeira etapa. Após 60 dias, foram avaliados a percentagem de germinação e o índice de velocidade de germinação (Larré et al., 2007) e comparados quantitativamente por meio de regressão polinomial (Programa Sisvar - Ferreira, 2000). As avaliações do IVG foram realizadas diariamente até a estabilização da germinação (Silva \& Nakagawa, 1995).

\section{$2^{a}$ Etapa}

Para a realização do experimento foram utilizados segmentos nodais uniformes, com cerca de $2 \mathrm{~cm}$, contendo duas gemas, oriundos das sementes germinadas in vitro da primeira etapa.

Os meios testados foram MS (Murashige \& Skoog, 1962), MSM (Monteiro-Hara, 2000), BDS (Dunstan \& Short, 1977), DSD1 (Silva \& Doazan, 1995) e WPM (Lloyd \& McCown, 1980), cada um adicionado de $100 \mathrm{mg} \mathrm{L}^{-1} \mathrm{de}$ mio-inositol, quatro concentrações de sacarose $(0,15,30$ e 45 g.L $L^{-1}$ ) e sem adição de reguladores de crescimento. As vitaminas e os aminoácidos foram adicionados de acordo com cada meio de cultura utilizado.

$\mathrm{O} \mathrm{pH}$ de cada meio foi ajustado para 5,8 antes da adição de $6,0 \mathrm{mg} \mathrm{L}^{-1}(0,6 \%)$ de ágar. Após o preparo, $15 \mathrm{~mL}$ do meio de cultura foram distribuídos em tubos de ensaio, os quais foram vedados com tampas de polipropileno, identificados e autoclavados a $121^{\circ} \mathrm{C}$, por 20 minutos.

Os ensaios foram instalados em condições assépticas em câmaras de fluxo laminar horizontal, que foram desinfestadas com álcool 70\%. Os instrumentos (pinças, bisturis e placas de Petri ${ }^{\circledR}$ ) foram autoclavados e flambados. Os segmentos nodais foram obtidos uniformemente a partir de plâtulas pré-estabelecidas. Após a inoculação, os explantes foram mantidos por 60 dias em sala de crescimento, com luminosidade em torno de $35 \mu \mathrm{mol} . \mathrm{m}^{-2} . \mathrm{s}^{-1}$, temperatura $26 \pm 1{ }^{\circ} \mathrm{C}$ e fotoperíodo de 16 horas. As variáveis avaliadas foram comprimento da parte aérea $(\mathrm{cm})$, número de gemas, biomassa seca das plântulas (g) e número de raízes e de brotações laterais.

O delineamento experimental utilizado foi o inteiramente casualizado, em esquema fatorial $5 \times 4$ (cinco meios de cultivo x quatro concentrações de sacarose), com quatro repetições e três plantas por parcela.

Os dados foram submetidos à análise de variância, e os fatores quantitativos foram comparados por meio de regressão polinomial (Programa Sisvar - Ferreira, 2000) e os qualitativos pelo teste de Scott-Knott.

\section{RESULTADOS E DISCUSSÃO}

\section{$1^{a}$ Etapa}

Para todas as variáveis analisadas houve interação significativa entre modo de escarificação e concentração de GA.
Para a variável percentagem de germinação, obtevese melhor resultado (46,8\%) utilizando-se $19,84 \mathrm{mg} \mathrm{L}^{-1} \mathrm{de}$ $\mathrm{GA}_{3}$ e realizando a escarificação na ponta da semente ( $\mathrm{Fi}$ gura 1). Com o aumento nas concentrações de $\mathrm{GA}_{3}$, verificaram-se respostas crescentes quadráticas até o ponto de máximo, obtido com 19,84 $\mathrm{mg} \mathrm{L}^{-1}$, seguidas com redução na porcentagem de germinação em concentrações superiores. A baixa germinação às vezes é obtida em experimentos com espécies dormentes (Tedesco et al., 2001), sendo necessário desenvolver técnicas que permitam melhorar a germinação.

A embebição das sementes de Passifloráceas pode ser eficiente para promover a sua germinação, segundo alguns autores. Ferreira (1998) verificou que a imersão de sementes de Passiflora alata em $100 \mathrm{mg} \mathrm{L}^{-1} \mathrm{de} \mathrm{GA}_{3}$ favoreceu a germinação. Em sementes sem arilo embebidas em 150 e $300 \mathrm{mg} \mathrm{L}^{-1}$ de ácido giberélico observou-se maior percentagem de germinação (Rossetto et al., 2000).

Verificou-se nas sementes que não foram escarificadas ausência de germinação, mesmo com a presença do $\mathrm{GA}_{3}$ no meio. Com isso, pode-se supor que a espécie possui algum tipo de dormência física. Morley-Bunker (1980) e Wagner Júnior et al. (2007) mencionaram que algumas espécies de Passiflora spp. apresentam dormência em suas sementes, ocasionada pelo mecanismo de controle da entrada de água, devido à dureza do tegumento, necessitando-se de tratamentos para a superação da dormência física.

O maior índice de velocidade de germinação (IVG) foi obtido com a utilização de $23,24 \mathrm{mg} \mathrm{L}^{-1} \mathrm{GA}_{3} \mathrm{e}$ escarificação da ponta da semente $(1,68)$ (Figura 2$)$. Assim, verificou-se que tanto a percentagem de germinação quanto o IVG foram maiores nas concentrações de $\mathrm{GA}_{3}$ em torno de $20 \mathrm{mg} \mathrm{L}^{-1}$. Segundo Taiz \& Zeiger (2004), as giberelinas estão envolvidas na quebra de

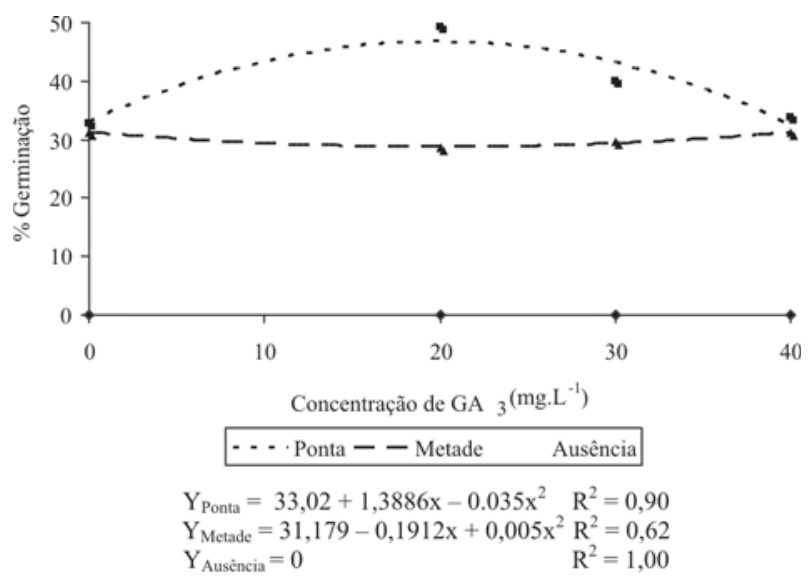

Figura 1. Percentagem de sementes de maracujazeiro-do-sono (Passiflora setacea DC.) germinadas em meio de cultivo MS acrescido de 0 , 20, 30 e $40 \mathrm{mg} . \mathrm{L}^{-1}$ de $\mathrm{GA}_{3}$; combinados com a ausência de escarificação e escarificação na ponta e no meio da semente. 


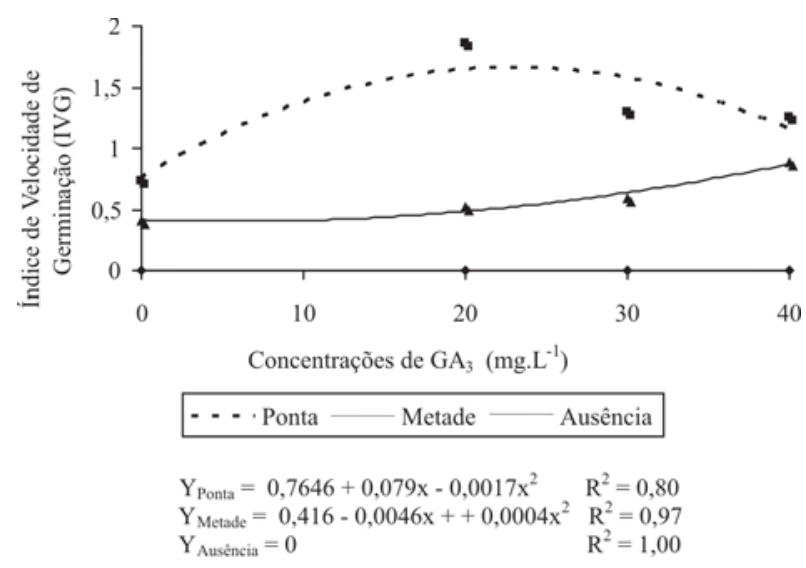

Figura 2. Índice de velocidade de germinação de sementes de maracujazeiro-do-sono (Passiflora setacea DC.) em meio de cultivo MS acrescido de 0, 20, 30 e $40 \mathrm{mg} \mathrm{L}^{-1}$ de $\mathrm{GA}_{3}$, combinados com a ausência de escarificação e escarificação na ponta e no meio da semente.

dormência de sementes de diferentes espécies, provocando a diminuição no tempo médio de germinação e aumentando o índice de velocidade de germinação, conforme verificado neste trabalho.

\section{$2^{a}$ Etapa}

Observa-se que houve efeito significativo para a interação meio de cultura $\mathrm{x}$ concentrações de sacarose nas características comprimento da parte aérea, número de gemas e peso da matéria seca das plântulas.

De acordo com a análise de regressão, melhores resultados para o comprimento da parte aérea $(5,44 \mathrm{~cm})$ e número de gemas $(11,47 \mathrm{~cm})$ foram obtidos com a utilização do meio de cultura MSM associado com 29,96 e 28,74 g.L${ }^{1}$ de sacarose, respectivamente (Figuras 3 e 4).

Diferentes respostas foram observadas para o comprimento da parte aérea e número de gemas nos meios de cultivo utilizados. Tanto o crescimento quanto a morfogênese em culturas in vitro são sensivelmente influenciados pela disponibilidade de $\mathrm{N}$ (nitrogênio) e a forma em que ele é fornecido. O MSM possui concentração de sais (macro e micronutrientes) considerada baixa, porém benéfica na micropropagação de fruteiras (Pasqual, 2001).

O aumento das concentrações de sacarose proporcionou incremento de forma quadrática no comprimento da parte aérea dos explantes até $30 \mathrm{~g} \mathrm{~L}^{-1}$, verificando-se decréscimos dessa variável em maiores concentrações, independentemente do meio de cultivo utilizado. Provavelmente, isso ocorreu devido ao aumento excessivo do potencial osmótico do meio de cultura, que dificultou o desenvolvimento das brotações (Figura 3).

Na Figura 4 verificaram-se diferenças significativas entre os meios de cultura empregados, associados às concentrações de sacarose, em relação ao número de gemas das plântulas. Essas diferentes respostas podem ser relacionadas ao teor de sais do meio de multiplicação, pois uma concentração maior ou menor de sais, ou outros compostos osmoticamente ativos, de acordo com a espécie e com o potencial osmótico de suas sementes, poderá ser o fator responsável pela sua adequada hidratação, viabilizando ou não a ocorrência de gemas (Dodd \& Donovan, 1999).

Para muitas espécies, a sacarose é empregada nos meios de cultura em concentrações variando entre 2 e 4\%. Segundo Grattapaglia \& Machado (1998), abaixo desta faixa pode ocorrer o aparecimento de clorose generalizada da cultura e acima, problemas de excessivo potencial osmótico do meio, o que leva a deterioração das plântulas. Porém, acima de $45 \mathrm{~g} \mathrm{~L}^{-1}$ de sacarose adicionada aos meios de cultivo observou-se maior massa da matéria seca das plântulas (Figura 5).

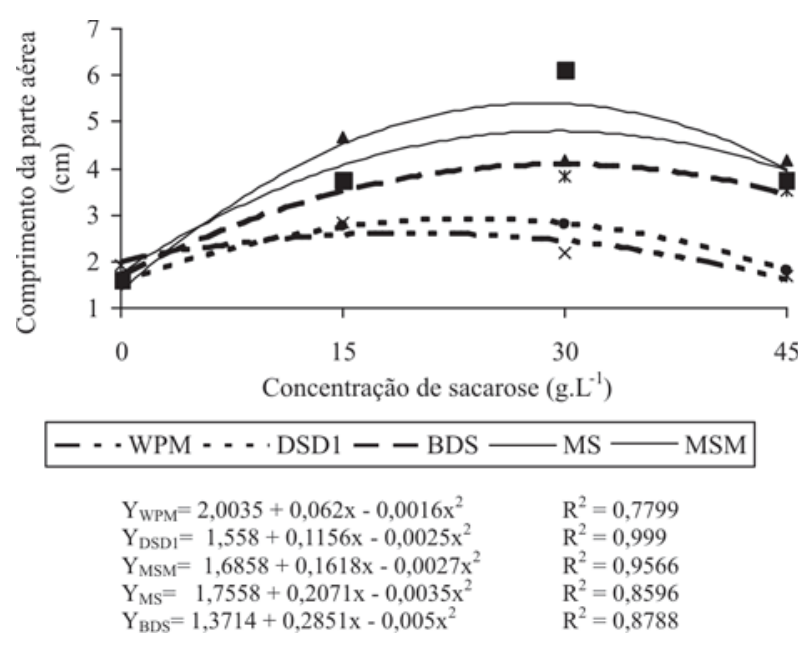

Figura 3. Comprimento da parte aérea de plântulas de maracujazeiro-do-sono (Passiflora setacea DC.) em diferentes meios de cultivo acrescidos de diferentes concentrações de sacarose.

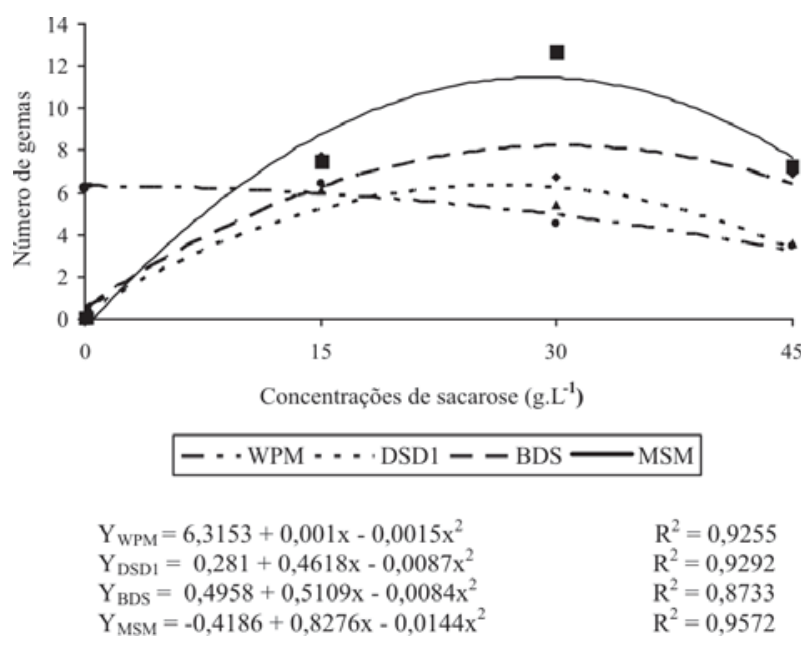

Figura 4. Número de gemas por plântula de maracujazeiro-do-sono (Passiflora setacea DC.) em diferentes meios de cultivo acrescidos de diferentes concentrações de sacarose. 


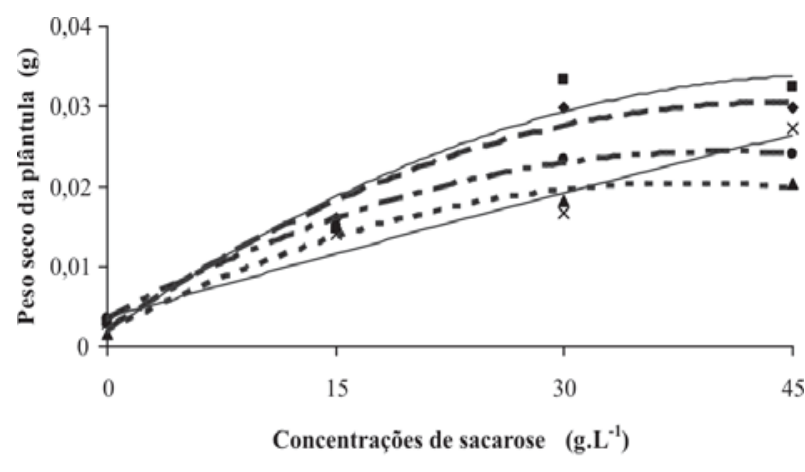

\begin{tabular}{|c|c|}
\hline \multicolumn{2}{|c|}{-- BDS $\cdots$ DSD1 $\longrightarrow$ MS $\longrightarrow$ MSM $-\cdots$ WPM } \\
\hline$Y_{\mathrm{BDS}}=0,002+0,0013 \mathrm{x}-0,00005 \mathrm{x}^{2}$ & $\mathrm{R}^{2}=0,9798$ \\
\hline $\mathrm{Y}_{\mathrm{DSD} 1}=0,002+0,001 \mathrm{x}-0,00005 \mathrm{x}^{2}$ & 0,9811 \\
\hline $\mathrm{Y}_{\mathrm{MS}}=0,0036+0,0005 \mathrm{x}-0,000001 \mathrm{x}^{2}$ & $=0,9566$ \\
\hline$Y_{M S M}=0,0018+0,0013 x-0,000014 x^{2}$ & $\mathrm{R}^{2}=0,9467$ \\
\hline$Y_{\text {WPM }}=0,0034+0,001 x-0,000013 x^{2}$ & $\mathrm{R}^{2}=0,9993$ \\
\hline
\end{tabular}

Figura 5. Massa de peso seco de plântulas de maracujazeiro-dosono (Passiflora setacea DC.) em diferentes meios de cultivo acrescidos de diferentes concentrações de sacarose.

Não se verificou a presença de raízes e de brotações laterais em todos os tratamentos do ensaio. Supõe-se que as concentrações de sacarose adicionadas aos diversos meios de cultura possam ter influenciado negativamente na formação do sistema radicular das plântulas de Passiflora setacea.

Junghans et al. (2002) observaram que microplantas de P. edulis f. flavicarpa O. Deg. atingiram o máximo de enraizamento quando se reduziu a concentração do meio de cultura. Os mesmos autores relataram a ação benéfica de maiores concentrações de sacarose no enraizamento do maracujazeiro.

A sacarose como fonte de carboidratos visa suprir às necessidades metabólicas dos explantes, atuando como fonte de esqueletos carbônicos na diferenciação celular e no crescimento (De Riek et al., 1997). Talvez a quantidade de açúcar endógena das plântulas fosse suficiente para a formação de raízes e brotações, satisfazendo suas necessidades metabólicas.

\section{CONCLUSÕES}

O método de escarificação na ponta da semente, juntamente com a utilização de $19,84 \mathrm{mg} \mathrm{L}^{-1}$ de $\mathrm{GA}_{3}$ no meio de cultura, mostra-se efetivo para quebra parcial da dormência das sementes do maracujazeiro-do-sono.

Segmentos nodais do maracujazeiro-do-sono em meio MSM com 29,96 $\mathrm{g} \mathrm{L}^{-1}$ de sacarose permitem maior crescimento das brotações.

\section{REFERÊNCIAS}

Bernacci, LC, Meletti LMM, Soares-Scott MD, Passos IRS \& Junqueira NT (2005) Espécies de maracujá: caracterização e conservação da biodiversidade. In: Faleiro F, Junqueira N \& Braga M (Org.) Maracujá: germoplasma e melhoramento genético. $1^{\text {a }}$ ed. Planaltina, Embrapa Cerrados. p.559-586.
Braga MF, Santos EC, Junqueira NTV, Sousa AATC, Faleiro FG, Rezende LN \& Junqueira KP (2006) Enraizamento de estacas de três espécies silvestres de Passiflora. Revista Brasileira de Fruticultura, 28:284-288.

De Riek J, Piqueras A \& Debergh PC (1997) Sucrose uptake and metabolism in a double layer system for micropropagation of Rosa multiflora. Plant Cell, Tissue and Organ Culture, 47:269278.

Dodd GL \& Donovan LA (1999) Water potential and ionic effects on germination and seedling growth of two cold desert shrubs. American Journal of Botany, 86:1146-1153.

Dunstan DI \& Short KC (1977) Improved growth of tissue cultures of the onion (Allium cepa). Physiologia Plantarum, 41:70-72.

Ferreira DF (2000) Análises estatísticas por meio do Sisvar para Wiows versão 4.0. In: 45 ${ }^{\mathrm{a}}$ Reunião Anual da Região Brasileira da Sociedade Internacional de Biometria, São Carlos. Anais, UFSCar. p.255-258.

Ferreira G (1998) Estudo da embebição e efeito de fitorreguladores na germinação de sementes de Passifloráceas. Tese de doutorado. Universidade Estadual Paulista, Botucatu, 146p.

Grattapaglia D \& Machado MA (1998) Micropropagação. In: Torres AC \& Caldas LS (Eds.) Técnicas e aplicações da cultura de tecidos de plantas. Brasília: ABCTP/ EMBRAPA/CNPH. p.99160.

IBGE. 2005. Banco de Dados Agregados. Sistema IBGE de Recuperação Automática - SIDRA. Disponível em: <http:// www.sidra.ibge.gov.br/bda>. Acessado em: 07 de junho de 2009.

Junghans TG, Vidal AM \& Souza AS (2002) Cultivo in vitro de ápices caulinares de maracujazeiro amarelo em função do meio de cultivo e temperatura. In. $17^{\circ}$ Congresso Brasileiro de Fruticultura: Os Novos Desafios da Fruticultura Brasileira, Belém. Anais, 1 CD-ROM.

Junqueira NTV, Braga MF, Faleiro FG, Peixoto JR \& Bernacci LC (2005) Potencial de espécies silvestres de maracujazeiro como fonte de resistência a doenças. In: Faleiro FG, Junqueira NTV \& Braga MF(Org.) Maracujá: germoplasma e melhoramento genético. Planaltina, EMBRAPA Cerrados. p.81-106.

Larré, CF, Zepka, APS \& Moraes, DM (2007) Testes de germinação e emergência em sementes de maracujá submetidas a envelhecimento acelerado. Revista Brasileira de Biociências, 5:708710.

Lloyd G \& McCown B (1980) Commercially feasible micropropagation of mountain laurel Kalmia latifolia by use of shoot-tip culture. Proceedings of International Plant Propagation Society, 30:421-427.

Manica I, Brancher A, Sanzonowicz C, Icuma IM, Aguiar JLP, Azevedo JA, Vasconcellos MAS \& Junqueira NTV (2005) Maracujá-doce: tecnologia de produção, pós-colheita, mercado. $1^{\mathrm{a}}$ ed. Porto Alegre, Cinco Continentes. 198p.

Meletti LMM, Furlani PR, Álvares V, Soares-Scott MD, Bernacci LC \& Filho JAA (2002) Novas tecnologias melhoram a produção de mudas de maracujá. O agronômico, 54:30-33.

Monteiro-Hara ACBA (2000) Cultivo in vitro de três espécies do gênero Passiflora. Dissertação de Mestrado. Escola Superior de Agricultura “Luiz de Queiroz”, Piracicaba, 82p.

Morley-Bunker MJS (1980) Seed coat dormancy in Passiflora species. Annual Journal of the Royal New Zeland Institute of Horticulture, 8:72-84.

Murashige T \& Skoog F (1962) A revised medium for rapid growth and bioassays with tobacco tissue cultures. Physiologia Plantarum, 15:473-497. 
Pasqual M (2001) Cultura de tecidos vegetais: tecnologia e aplicações: meios de cultura. $1^{\mathrm{a}}$ ed. Lavras, UFLA/FAEPE, 74p.

Passos IRS \& Bernacci LC (2005) Cultura de tecidos aplicada à manutenção de germoplasma in vitro e ao melhoramento genético do maracujá (Passiflora spp.). In: Faleiros F, Junqueira N \& Braga M (Org.) Maracujá: germoplasma e melhoramento genético. $1^{\text {a }}$ ed. Planaltina, EMBRAPA Cerrados. p.361-383.

Rossetto CAV, Coneglian RCC, Nakagawa J, Shimizu MK \& Marin VA (2000) Germinação de sementes de maracujá-doce (Passiflora alata Dryand) em função de tratamento prégerminativo. Revista Brasileira de Sementes, 22:247-252.

Ruggiero C (2000) Situação do maracujazeiro no Brasil. Informe Agropecuário, 21:5-9.

Silva AL \& Doazan JP (1995) Une méthode d’irradiation aux rayons gamma appliquée à des porte-greffes de vigne in vitro. Journal International des Sciences de la Vigne et du Vin, 29:1-9.
Silva JBC \& Nakagawa J (1995) Estudo de fórmulas para cálculos da velocidade de germinação. Informativo ABRATES, 5:62-73.

Sousa JSI \& Meletti LMM (1997) Maracujá: espécies, variedades e cultivos. $1^{\text {a }}$ ed. Piracicaba, Editora FEALQ. 179p.

Taiz L \& Zeiger E (2004) Fisiologia vegetal. $3^{\text {a }}$ ed. Porto Alegre, Artmed. 719p.

Tedesco SB, Stefanello MO, Schifino-Wittmann MT, Battistin A \& Dall1Agnol M (2001) Superação de dormência em sementes de espécies de Adesmia DC. (Leguminosae). Revista Brasileira de Agrociência, 7:89-92.

Wagner Júnior A, Negreiros JRS, Alexandre RS, Pimentel LD \& Bruckner CH (2007) Efeito do pH da água na embebição e do trincamento das sementes de maracujazeiro amarelo na germinação e desenvolvimento inicial. Ciência e Agrotecnologia, 31:1014-1019. 